\title{
Unit vector template generator applied to a new control algorithm for an UPQC with instantaneous power tensor formulation, a simulation case study
}

\author{
Yeison Alberto Garcés Gómez ${ }^{1}$, Nicolás Toro García ${ }^{2}$, Fredy Edimer Hoyos ${ }^{3}$ \\ ${ }^{1}$ Universidad Católica de Manizales-Unidad Académica de Formación en Ciencias Naturales y Matemáticas, Colombia \\ ${ }^{2}$ Universidad Nacional de Colombia-Sede Manizales, Department of Electrical and Electronics Engineering and \\ Computer Sciences, Colombia \\ ${ }^{3}$ Universidad Nacional de Colombia Sede Medellín Facultad de Ciencias, Escuela de Física, Colombia
}

\begin{tabular}{ll}
\hline Article Info & ABSTRACT \\
\cline { 1 - 3 } Article history: & $\begin{array}{l}\text { In this paper we present a new algorithm to generate the reference signals to } \\
\text { control the series and parallel power inverters in a unified power quality } \\
\text { conditioner "UPQC" to enhance power quality. The algorithm is based on } \\
\text { the instantaneous power tensor formulation which it is obtained by the dyadic } \\
\text { Revised Mar 3, 2020 } \\
\text { Accepted Mar 12, } 2020\end{array} \quad \begin{array}{l}\text { product between the instantaneous vectors of voltage and current in n-phase } \\
\text { systems. The perfect harmonic cancellation algorithm "PHC" to estimate } \\
\text { the current reference in a shunt active power filter was modified to make it }\end{array}$ \\
$\begin{array}{l}\text { Keywords: } \\
\text { hardy to voltage sags through unit vector template generation "UVGT" while } \\
\text { from the same algorithm it extracts the voltage reference for series active } \\
\text { power filter. The model was validated by mean of simulations in } \\
\text { Power tensor }\end{array}$ & $\begin{array}{l}\text { Matlab-Simulink }{ }^{\circledR} . \\
\text { Shunt inverter }\end{array}$
\end{tabular}

Copyright (C) 2020 Institute of Advanced Engineering and Science. All rights reserved.

\section{Corresponding Author:}

Fredy Edimer Hoyos,

Universidad Nacional de Colombia Sede Medellín Facultad de Ciencias,

Escuela de Física,

Carrera 65 No. 59A-110, Colombia.

Email: fehoyosve@unal.edu.co

\section{INTRODUCTION}

The UPQC are power electronic devices that act like controlled voltage and current sources in power systems so that it can remove or reduce the effect of power quality issues like harmonics, sags, swells, imbalances in power source or loads and also lead to improve the power factor $[1,2]$. The growing interest in UPQCs come from last century, and since the concept of "power quality" has been gaining increasing popularity in the field of electrical engineering, today, it has become a great topic for companies providing electricity service, equipment manufacturers and end users, that leading to solutions searching to solve the problems of power quality [3-8].

Regarding the estimation algorithms of reference signal, many theories and methods have been proposed to define the control signals to correct the problems of power quality either voltage or current, which highlights the use of the instantaneous active and reactive power theory or pq theory, as one of the theories most used in order to generate reference currents in the shunt active power filters and UPQC; while often the estimation of sequence components and phase-looked-loops "PLL" are used for the voltage reference estimation and the grid synchronization with the filters, respectively [9, 10]. 


\section{DISTRIBUTED GENERATOR INTEGRATED WITH UPQC}

Furthermore, the interest in distributed generation systems such as wind and solar power is increasing, so has raised the use of one or more distributed generation systems in UPQCs that require injection of active power to the compensated system [11-18]. This type of system has the advantage that it can to control power quality problems either in voltage and current. Besides it can also mitigate sags and swells, it can act likea power source to provide energy to load in blackouts if there is integrated with a storage power system likea battery bank. The basic configuration of those systems is illustrated in Figure 1. Here we show the distributed generation system connected to DC bus of UPQC.

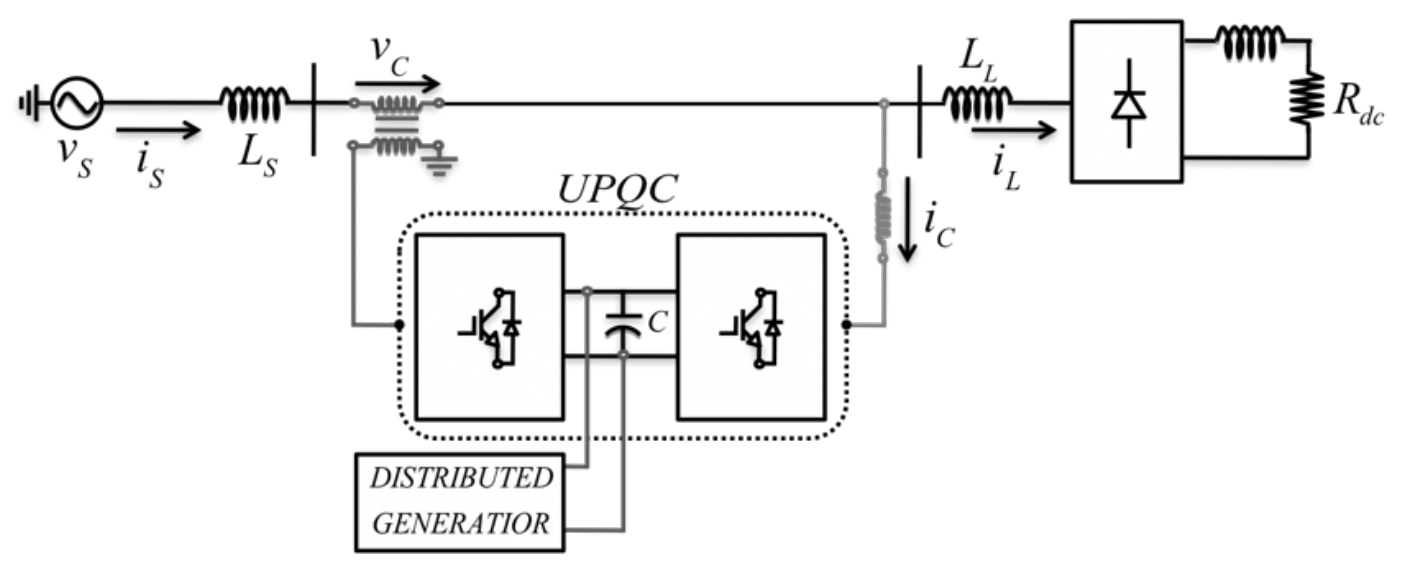

Figure 1. UPQC-DG system configuration

\section{INSTANTANEOUS POWER TENSOR FORMULATION}

The tensor formulation of instantaneous power proposed by Herrera et al $[18,19]$, and thereafter defined like "Instantaneous Power Tensor Theory" by Ustariz et al [20, 21], is based on the interpretation of the instantaneous voltage and current vectors like first order tensors, and then to define the power components by the dyadic product in a n-phase system, and proposing compensation models for the same type of system. From vectors $\vec{u}=\boldsymbol{u}=\left[\begin{array}{llll}u_{1} & u_{2} & \cdots & u_{n}\end{array}\right]$ an $\vec{\imath}=\boldsymbol{i}=\left[\begin{array}{llll}i_{1} & i_{2} & \cdots & i_{n}\end{array}\right]$ d Herrera et al., [18, 19] defines the active power $p(t)$ and the imaginary power $q(t)$ like:

$$
\begin{aligned}
& p(t)=\vec{u} \bullet \vec{\imath}=u^{T} i \\
& q(t)=\vec{\imath}(t) \wedge \vec{u}(t)
\end{aligned}
$$

where, $\wedge$ denotes the outer product, that is an antisymmetrization of dyadic product denoted by the operator $\otimes$, so that:

$$
q(t)=\vec{\imath}(t) \wedge \vec{u}(t)=(\vec{\imath} \otimes \vec{u})-(\vec{u} \otimes \vec{\imath})
$$

besides the components of the current is defined as follows:

$$
\vec{\imath}_{p}=\frac{p(t)}{\boldsymbol{u}^{T} \boldsymbol{u}} \boldsymbol{u}=\frac{\left(u_{1} i_{1}+u_{2} i_{2}+\cdots+u_{n} i_{n}\right)}{\vec{u} \bullet \vec{u}}\left[\begin{array}{c}
u_{1} \\
u_{2} \\
\vdots \\
u_{n}
\end{array}\right]
$$

expression equivalent to:

$$
\vec{\imath}_{p}=\frac{(\vec{u} \otimes \vec{\imath})}{\vec{u} \bullet \vec{u}} \vec{u}
$$

Moreover, the total current demand for the load is expressed as:

$$
\vec{\imath}=\frac{(i \otimes \vec{u})}{\vec{u} \bullet \vec{u}} \vec{u}=\frac{[(\vec{u} \otimes \vec{i})+(i \vec{u} \vec{u})-(\vec{u} \otimes \vec{i})]}{\vec{u} \bullet \vec{u}} \vec{u}=\frac{(\vec{u} \otimes \vec{i})}{\vec{u} \cdot \vec{u}} \vec{u}+\frac{[(i \otimes \vec{u})-(\vec{u} \otimes \vec{u}]}{\vec{u} \bullet \vec{u}} \vec{u}=\frac{(\vec{u} \otimes \vec{i})}{\vec{u} \bullet \vec{u}} \vec{u}+\frac{(\vec{i} \wedge \vec{u})}{\vec{u} \cdot \vec{u}} \vec{u}=\frac{p(t)}{\vec{u} \bullet \vec{u}} \vec{u}+\frac{q(t)}{\vec{u} \cdot \vec{u}} \vec{u}
$$


Finally, the decomposition of the current leads to the expression (7):

$$
\vec{\imath}=\vec{\imath}_{p}+\vec{\imath}_{q}
$$

The power and current components defined by Ustariz [20, 21] are self-same to Herrera, although the development of Ustariz shown at a slightly form more elegant the tensorial formulation from the definition of the instantaneous power tensor $\wp$ in (8). Thus, for an n-phase system, the instantaneous power tensor is given by:

$$
\wp_{i j}=\left[\begin{array}{c}
v_{1} \\
v_{2} \\
\vdots \\
v_{n}
\end{array}\right] \otimes\left[\begin{array}{llll}
i_{1} & i_{2} & \cdots & i_{n}
\end{array}\right]=\left[\begin{array}{cccc}
v_{1} i_{1} & v_{1} i_{2} & \cdots & v_{1} i_{n} \\
v_{2} i_{1} & v_{2} i_{2} & \cdots & v_{2} i_{n} \\
\vdots & \vdots & \ddots & \vdots \\
v_{n} i_{1} & v_{n} i_{2} & \cdots & v_{n} i_{n}
\end{array}\right]
$$

from (7 and 8), Ustariz performed the decomposition of one instantaneous power tensor in two, called active power tensor $\left({ }^{p} \wp_{i j}\right)$ and reactive power tensor $\left({ }^{q} \wp_{i j}\right)$, like in (9):

$$
\wp_{i j}=\vec{u} \otimes \vec{\imath}=\vec{u} \otimes\left(\vec{\imath}_{p}+\vec{\imath}_{q}\right)=\left(\vec{u} \otimes \vec{\imath}_{p}\right)+\left(\vec{u} \otimes \vec{\imath}_{q}\right)=\left({ }^{p} \wp_{i j}\right)+\left({ }^{q} \wp_{i j}\right)
$$

finally, the current components are defined as follows:

$$
\begin{aligned}
& \vec{\imath}_{p}=\frac{(\vec{u} \otimes \vec{\imath})}{\|\vec{u}\|^{2}} \vec{u} \\
& \vec{\imath}_{q}=\frac{(\vec{\imath} \otimes \vec{u})-(\vec{u} \otimes \vec{\imath})}{\|\vec{u}\|^{2}} \vec{u}
\end{aligned}
$$

becoming clear, the expressions in (10 and 11) by Ustariz are the same as defined in (5 and 6) by Herrera.

\section{SHUNT INVERTER CONTROL ALGORITHM}

From the tensor formulation [18-21], several tech-niques have been proposed for compensation in shunt active filters, one of these is the technique of the perfect harmonic cancellation "PHC" at source. Estimation of reference for this control strategy for the active filter is given by:

$$
\vec{\imath}_{r e f}=\vec{\imath}-\vec{\imath}_{p_{-} f}^{+}
$$

in (12), $\vec{l}_{p_{-} f}^{+}$is the direct sequence and fundamental frequency, active instantaneous current vector, defined by:

$$
\vec{l}_{p_{-} f}^{+}=\frac{\operatorname{tr}\left(\bar{\wp}_{i j}\right)}{\frac{1}{T} \int_{T}\left(\vec{v}_{f}^{+} \cdot \vec{v}_{f}^{+}\right)} \vec{v}_{f}^{+}
$$

the expression (13) proposed by Ustariz et al, is equivalent to (14) proposed by Herrera:

$$
\vec{\imath}_{S}(t)=\frac{P}{U^{2}} \vec{u}
$$

where $U$ is the average norm of the voltage instantaneous vector, and $P=\operatorname{tr}\left(\bar{\wp}_{i j}\right)$ is named like average active power by Herrera or average instantaneous power tensor by Ustariz. Block diagram for current reference estimation by PHC technique is shown in Figure 2 [21].

For compensation of the reactive power at a fundamental frequency, the algorithm described in Figure 2 makes use of a block called "DSFC" (direct estimation algorithm sequence fundamental frequency) for the load voltage [22]. This algorithm uses the inverse transform of Fortescue for determining direct sequence and trigonometric operations for extracting the fundamental frequency defined by the fast Fourier transform. The algorithm supports wave forms unbalanced and non-sinusoidal, but unfortunately, the algorithm does not support sags and swells in voltage. It has been verified by simulation that, in voltage sags, the algorithm decreases proportionally the reference current, and therefore, does not have the expected complete compensation. 


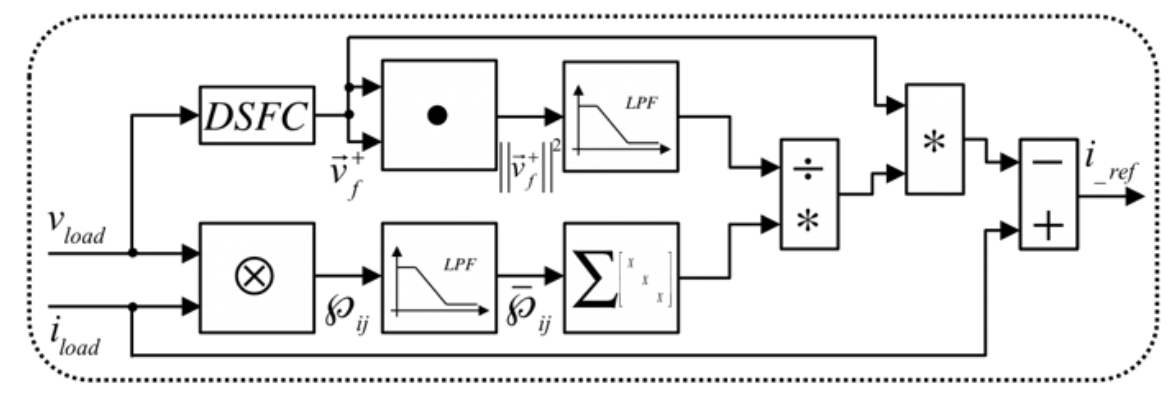

Figure 2. Block diagram for current reference estimation by PHC technique [21]

\section{SHUNT INVERTER CONTROL ALGORITHM}

As mentioned in the previous section, the PHC algorithm reported in [22] is not tolerant to variations in the power supply, such as sags and swells, which is why this algorithm has been modified to make it tolerant to these perturbations. The modification to the referenced, uses template generation unit vector (UVTG) for obtaining direct sequence voltages and fundamental frequency and a PLL in the synchronous reference system (SRF-PLL). The "UVTG" technique is well described in [23-25].

Extracting reference signals from the PLL and SFR-UVTG technique is sufficient to extract the reference signals of the active filter in series UPQC-DG inverter. In Figure 3 the complete diagram estimation references for unified power quality conditioner is illustrated. The voltage reference is set at (15).

$$
\vec{v}_{r e f}=\vec{v}_{p_{-} f}^{+}-\vec{v}_{\text {load }}
$$

In the diagram of Figure 3 the "UVT" block provides sinusoidal signals at unit value in phase with the fundamental component of the source voltage independent of its magnitude or harmonics condition.

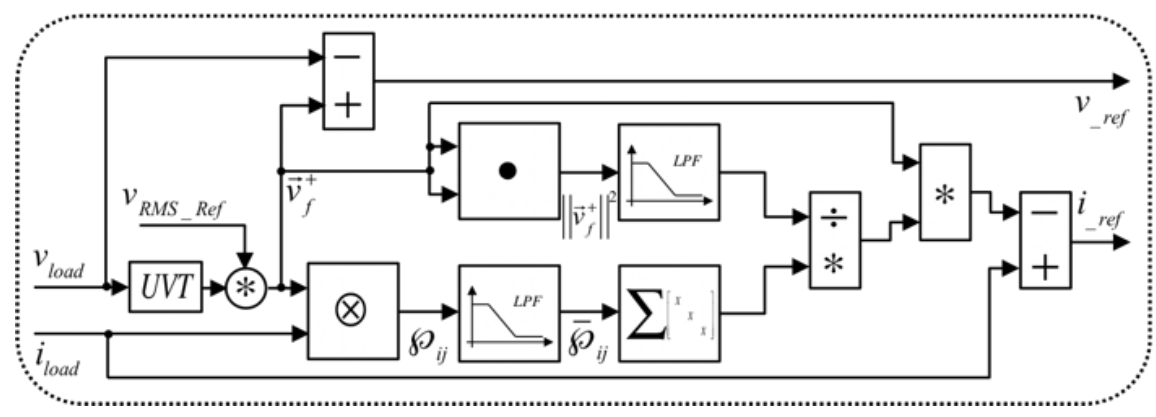

Figure 3. Block diagram for reference signal estimation of series and shunt inverters of the UPQC

\section{NUMERIC SOLUTION AND RESULTS}

The simulation corresponding to the algorithm regarding the generation of the reference was imple mented in Matlab-Simulink ${ }^{\circledR}$. The model has a voltage source distorted with harmonics for feeding a nonlinear load with a given current displacement factor to ensure control of the reactive power, the supply voltage is also applied to the system at some point of a voltage sag to verify that the algorithm is tolerant to these Figure 4. The inverters control loop has been made by hysteresis with fixed switching frequency $[26,27]$ with the same frequency in both switching inverter bridges, the model implemented for this control is illustrated in Figure 5. The first part is the error which is passed through a system that converts the error to binary values as stated in (16):

$$
\text { if }(\text { ref }- \text { out }) \geq 0 \Rightarrow \text { boolean }=1 \text {, else } \Rightarrow \text { boolean }=0
$$

Although the switching output of boolean type, is variable and depends on the dynamics of change in the measured error, in the D-type flip-flop, switching frequency is fixed at a constant value given by the block sequence (serving as clock) and can be set according to the inverter's design criteria. Although the literature has reported many methods of controlling inverters, we have implemented this model because it has a quick 
response and a low computational cost, which allows it to be easily programmed in current DSP based development systems.

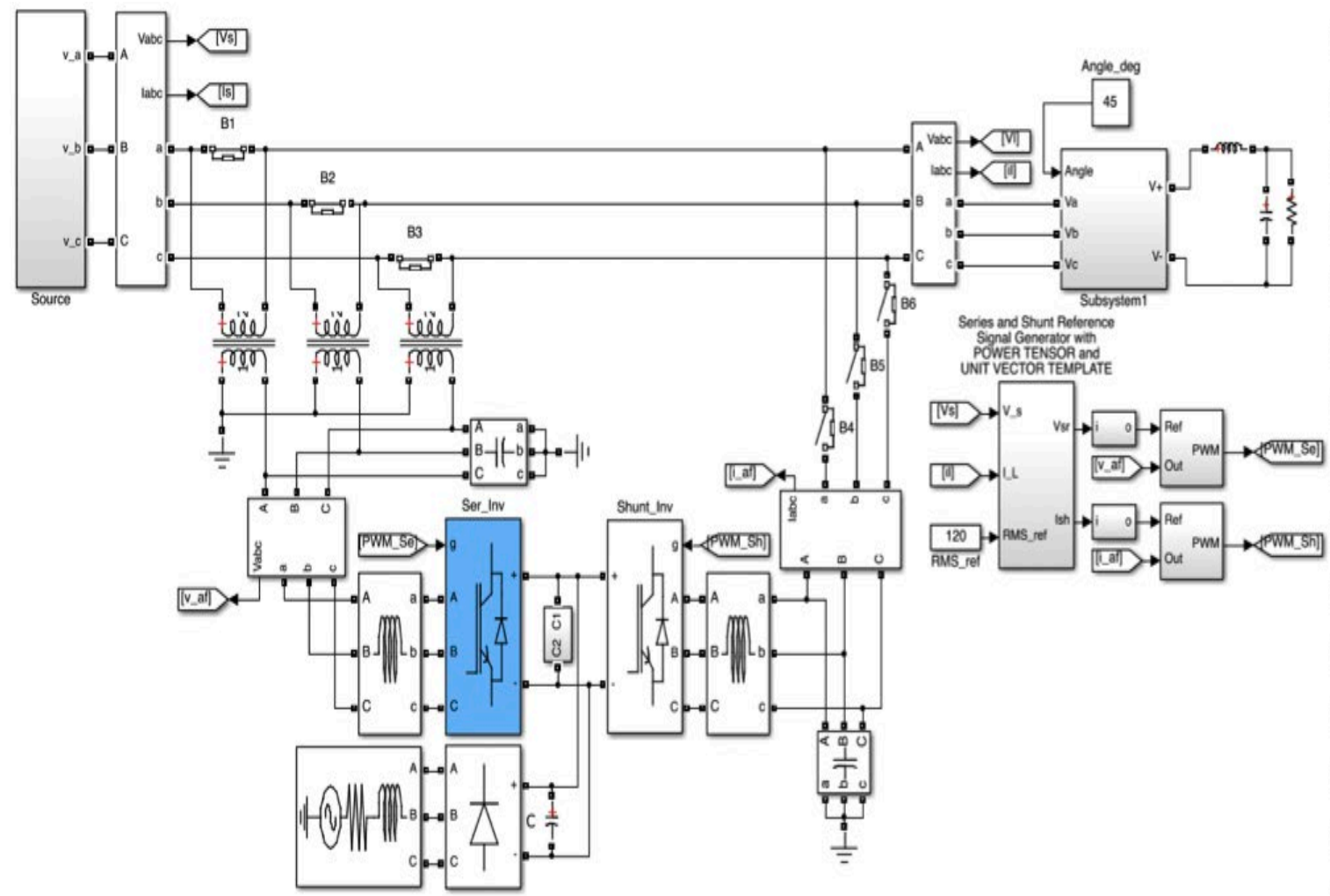

Figure 4. UPQC simulation model on matlab-simulink ${ }^{\circledR}$

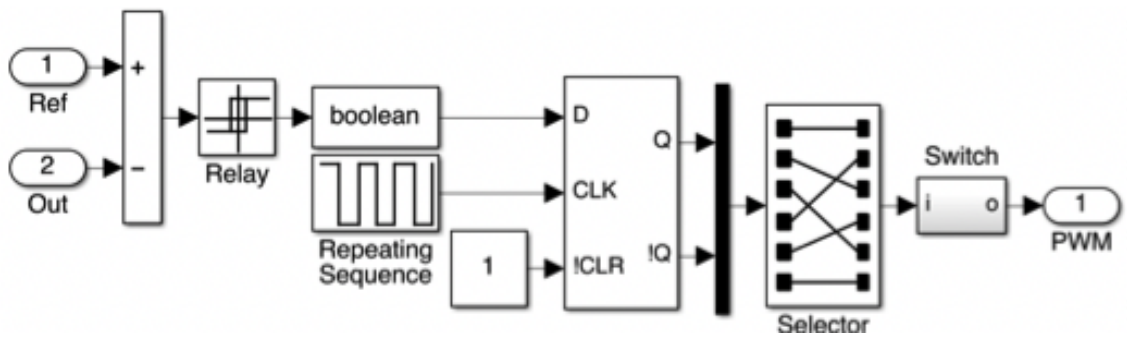

Figure 5. Hysteresis control with fixed switching frequency

In Figure 6, the waveform of one phase of the power supply and the RMS value over time of simulation are illustrated, it is heavily contaminated by harmonics, illustrating the effect of distorting the current loads on source impedances. Furthermore, a voltage sag of three cycles is shown to verify that the algorithm can compensate for such transients on the network. In this case we have simulated a drop in the RMS value of $30 \%$.

The UPQC is operated in four time intervals: in the first 3 cycles is not given compensation in voltage or current, in the second time interval, beginning at the 4rd cycle, the voltage compensation is only activated, in this range the series active filter compensates harmonics, isolating the load Figure 7 . At the point where the voltage dip is generated, it is observed how the compensation voltage of the series filter increases to make up for the drop. In the next interval, from the $6^{\text {th }}$ cycle, compensation of harmonics and reactive power in current is activated, in this case, the parallel inverter injects the compensation current needed to eliminate harmonics generated by the load and to carry the power factor to the unit. In the signals of reference can be seen that the length of the voltage sag time is compensated by an increase of the voltage signal reference. 


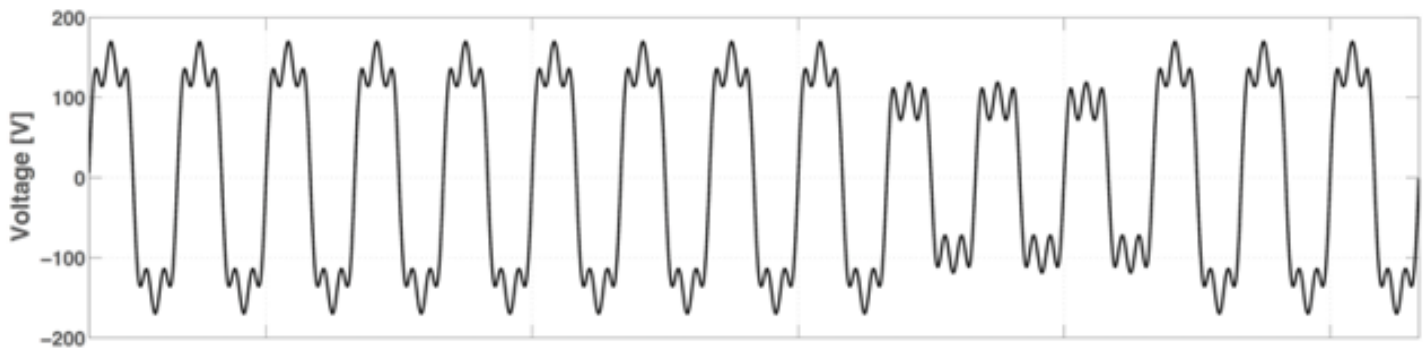

(a)

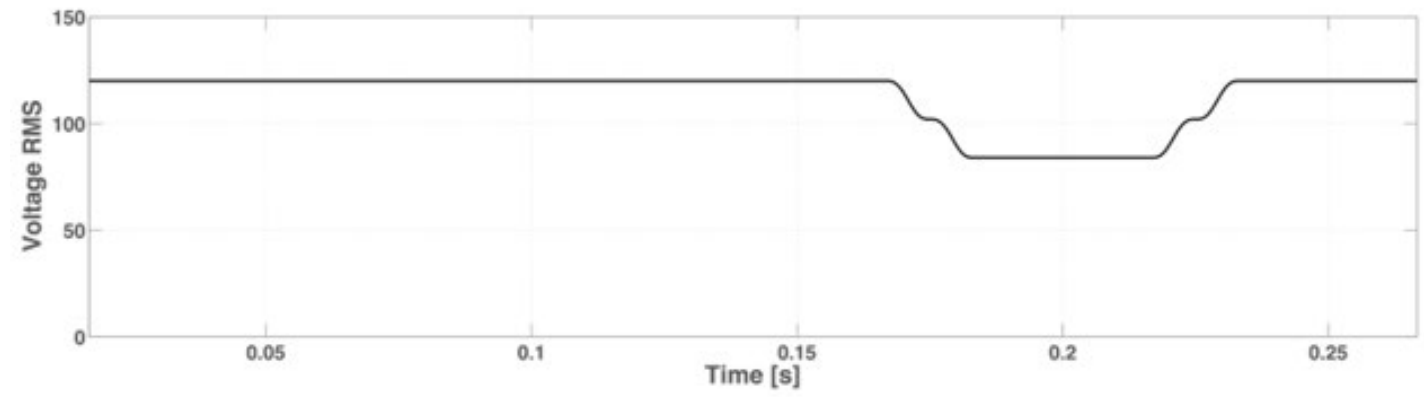

(b)

Figure 6. Harmonic polluted voltage source with SAG, (a) waveform, (b) RMS value

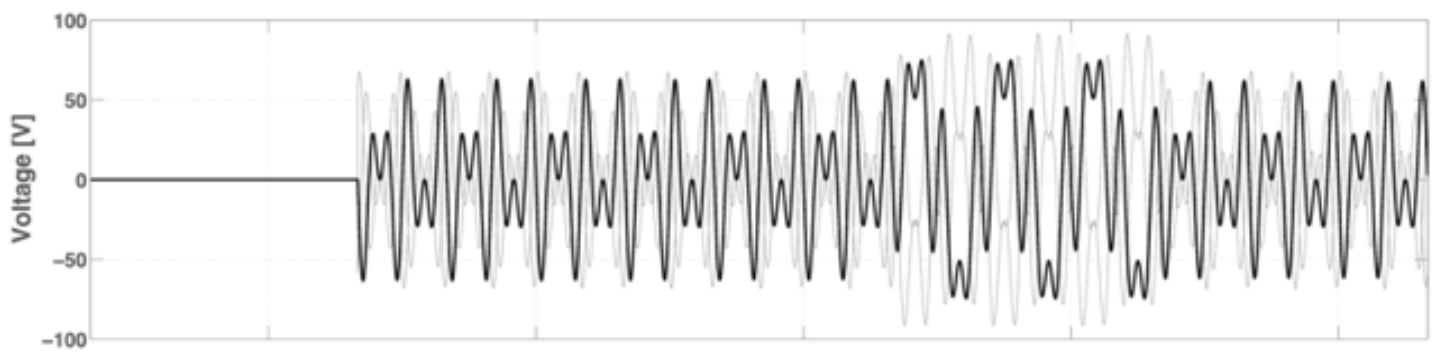

(a)

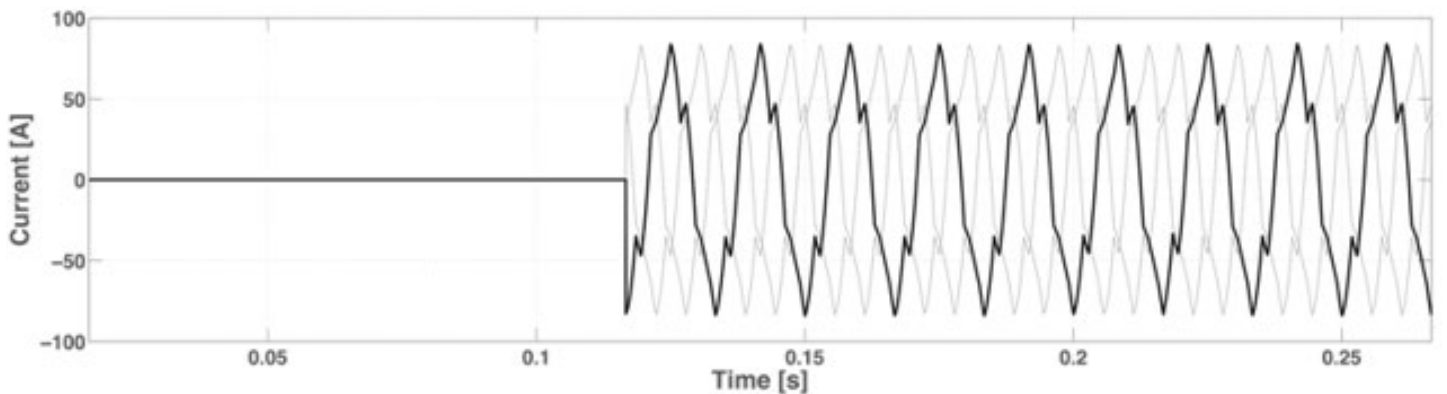

(b)

Figure 7. UPQC-DG waveform, (a) compensation voltages, (b) compensation currents

Figure 8 illustrates the voltage signals of the load and supply current throughout the simulation time. Finally, in Figure 9 the active and reactive power measurements are presented at the point of common connection, PCC. In this figure it is noted that performing the voltage compensation, the ripple of the active and reactive power is decreased, then the reactive power and the oscillating part of the active power are removed. At the time of the voltage sag, one component of active power and reactive oscillating arise due to the lack of compensation current produced by harmonics for having limited power in the distributed generator. Table 1 the most important simulation results are presented before and after compensation and during the voltage sag. 


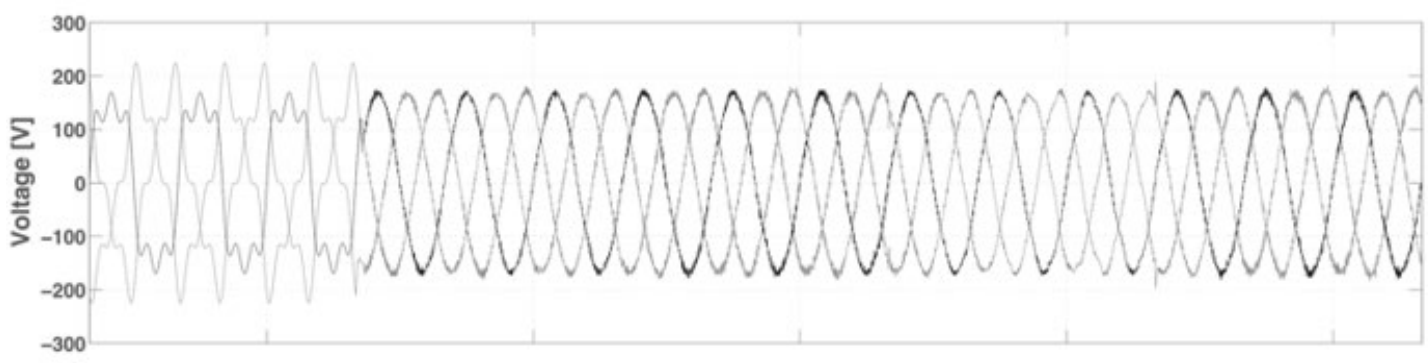

(a)

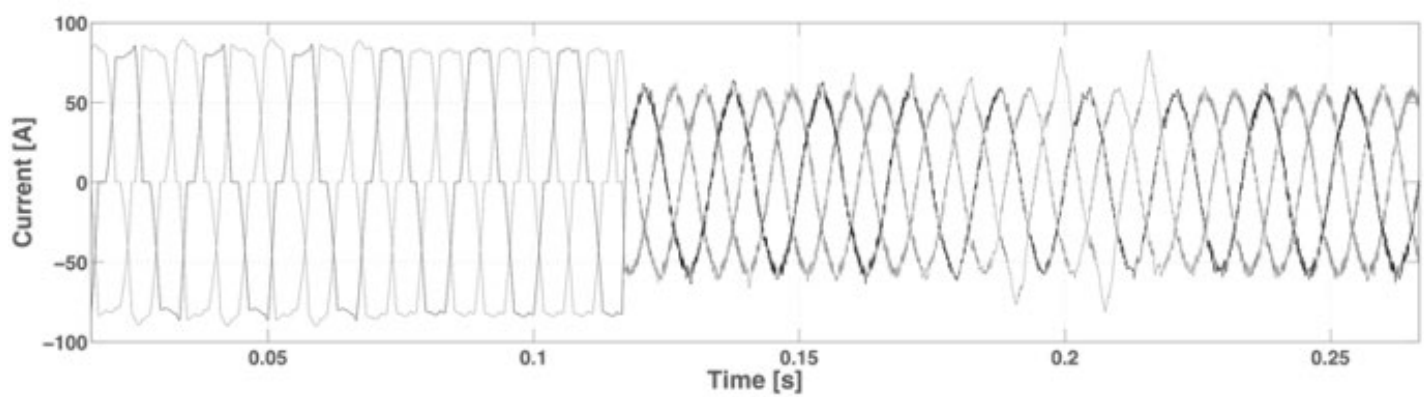

(b)

Figure 8. Load voltages and source currents waveforms, (a) load voltage, (b) source current

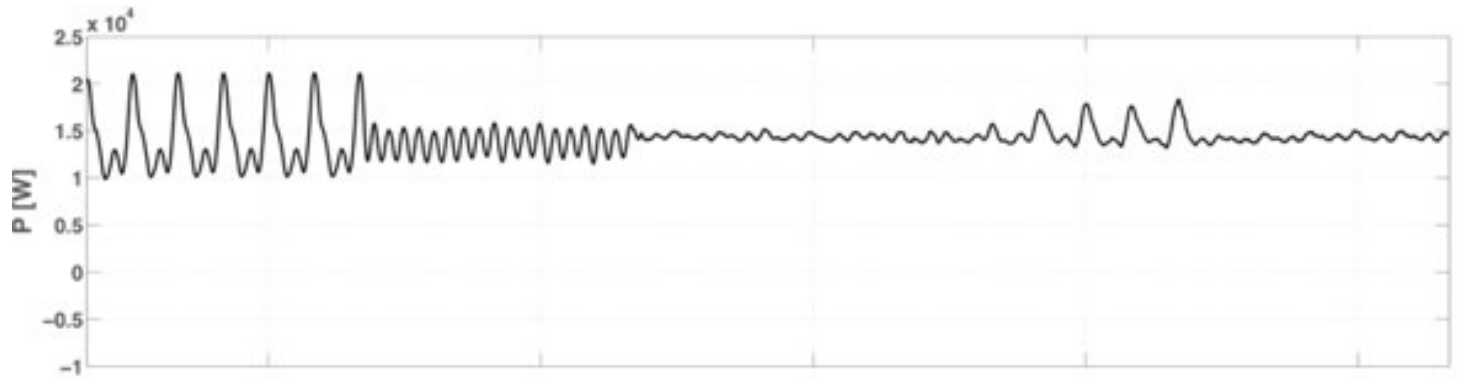

(a)

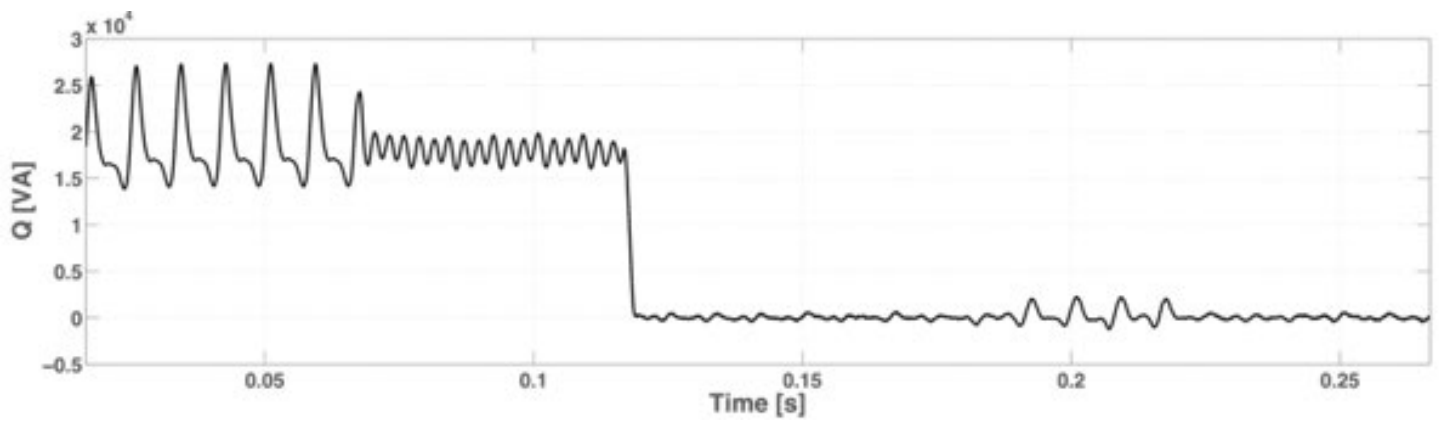

(b)

Figure 9. Power at PCC, (a) active power, (b) imaginary power

Table 1. Results of the main PQ indices

\begin{tabular}{cccc}
\hline Index & Before compensation & After compensation & During SAG \\
\hline RMS Current & $63 \mathrm{~A}$ & $40 \mathrm{~A}$ & $48 \mathrm{~A}$ \\
RMS Voltage & $120 \mathrm{~V}$ & $120 \mathrm{~V}$ & $84 \mathrm{~V}$ \\
THDv & $16.67 \%$ & $4.52 \%$ & $5.8 \%$ \\
THDi & $28.34 \%$ & $2.40 \%$ & $3.68 \%$ \\
\hline
\end{tabular}




\section{CONCLUSION}

A new algorithm to generate the reference signals to control the series and parallel power inverters in an unified power quality conditioner "UPQC" to enhance power quality was developed and the classic discrete control model was applied in a three-phase power grid with harmonic distortion and unbalance in the power source. Perfect harmonic cancellation algorithm "PHC" to estimate the current reference in a shunt active power filter was modified to make it hardy to voltage sags through unit vector template generation "UVGT". From the same algorithm it extracts the voltage reference for series active power filter. The results showed that the series and shunt APFs worked to give good efficiency in filtering the voltage harmonics of the source and the currents harmonics of the load, and to improve the power factor. The power compensator was able to isolate the load from a voltage sag generated at the source, showing that the algorithm can compensate transients.

\section{ACKNOWLEDGEMENTS}

This work was supported by the Universidad Católica de Manizales with the Research Groups on Technological and Environmental Development GIDTA, the Project "Espacios inhabitados, espacios resignificados. construyendo tejido social a través de la intervención comunitaria" and the Universidad Nacional de Colombia, Sede Medellín and Sede Manizales. This work was supported by the Universidad Nacional de Colombia, Sede Medellín under the Project HERMES-36911.

\section{REFERENCES}

[1] A. Amirullah, O. Penangsang, A. Soeprijanto, "Matlab/Simulink Simulation of Unified Power Quality ConditionerBattery Energy Storage System Supplied by PV-Wind Hybrid Using Fuzzy Logic Controller," International Journal of Electrical and Computer Engineering (IJECE), vol. 9, no. 3, pp. 1479-1495, Jun. 2019.

[2] M. Laxmidevi Ramanaiah, M. Damodar Reddy, "Moth Flame Optimization Method for Unified Power Quality Conditioner Allocation," International Journal of Electrical and Computer Engineering (IJECE), vol. 8, no. 1, pp. 530-537, Feb. 2018.

[3] Shafiuzzaman Khan Khadem, "Power Quality Improvement of Distributed Generation Integrated Network with Unified Power Quality Conditioner," Thesis Submitted for the Degree of Doctor of Philosophy to the Technological University Dublin, 2013.

[4] Salvador Pérez Litrán, “Análisis Y Diseño De Filtros Activos Serie E Híbrido Para La Mejora De La Calidad De La Potencia Eléctrica,” Tesis Doctoral de Salvador Pérez Litrán, 2011

[5] Ahmet Teke, "Unified Power Quality Conditioner: Design, Simulation and Experimental Analysis, University of C, Ukurovainstitute of Natural and Applied Science," Department of Electrical and Electronics Engineering, Adana, Turkey, Ph.D. Thesis, 2011.

[6] Xiaomeng Li, "Ultracapacitor Character Analysis and Its Application in Unified Power Quality Conditioner as Energy Storage System,” Missouri University of Science and Technology, Ph.D. Thesis, 2010.

[7] F.-Z. Peng, Hirofumi Akagi, and Akira Nabae, "A Study Of Active Power Filters Using Quad-Series VoltageSource PWM Converters For Harmonic Compensation," in IEEE Transactions on Power Electronics, vol. 5, no. 1, pp. 9-15, Jan. 1990.

[8] Fang Zheng Peng, Hirofumi Akagi, and Akira Nabae, "A New Approach To Harmonic Compensation In Power Systems-A Com-Bined System of Shunt Passive and Series Active Filters," in IEEE Transactions on Industry Applications, vol. 26, no. 6, pp. 983-990, Nov.-Dec. 1990.

[9] Ahmet Teke, "Unified Power Quality Conditioner: A Literature Survey," in Journal Electrical Systems, vol. 7, no. 1, pp. 122-130, Mar. 2011.

[10] Vinod Khadkikar, "Enhancing Electric Power Quality Using UPQC: A Comprehensive Overview," in IEEE Transactions on Power Electronics, vol. 27, no. 5, pp. 2284-2297, May 2012.

[11] Sung-Woo Park, Il-Yop Chung, Joon-Ho Choi, Seung-Il Moon, and Jae-Eon Kim, "Control Schemes of The Inverter-Interfaced Multi-Functional Dispersed Generation,” 2003 IEEE Power Engineering Society General Meeting (IEEE Cat. No.03CH37491), Toronto, Ont., vol. 3, pp. 1924-1929, 2003.

[12] B. Han, B. Bae, H. Kim, and S. Baek, "Combined Operation Of Unified Power-Quality Conditioner with Distributed Generation,” in IEEE Transactions on Power Delivery, vol. 21, no. 1, pp. 330-338, Jan. 2006.

[13] R. A. Mastromauro, M. Liserre, T. Kerekes, and A. Dell'Aquila, "A Single-Phase Voltage-Controlled GridConnected Photovoltaic System with Power Quality Conditioner Functionality," in IEEE Transactions on Industrial Electronics, vol. 56, no. 11, pp. 4436-4444, Nov. 2009.

[14] M. Davari, S. M. Ale-Emran, H. Yazdanpanahi, and G. B. Gharehpetian, "Modeling The Combination of UPQC and Photo-Voltaic Arrays With Multi-Input Single-Output DC-DC converter," in 2009 IEEE International Conference on Industrial Technology, Gippsland, VIC, pp. 1-6, 2009.

[15] H. Toodeji, S. H. Fathi, and G. B. Gharehpetian, "Power Management and Performance Improvement in Integrated System of Variable Speed Wind Turbine and UPQC," 2009 International Conference on Clean Electrical Power, Capri, pp. 609-614, 2009.

[16] A. Mokhtarpour, M. Bathaee, and H. A. Shayanfar, "Power Quality Compensation in Smart Grids with A Single Phase UPQC- DG,” Iranian Conference on Smart Grids, Tehran, pp. 1-5, 2012. 
[17] N. Saudin et al., "Study on the Effect Of Distributed Generation Towards Unified Power Quality Conditioner Performance In Miti-Gating Voltage Sags, in Power and Energy (PECon)," 2012 IEEE International Conference on Power and Energy (PECon), Kota Kinabalu, pp. 695-700, 2012.

[18] R. S. Herrera, P. Salmeron, J. R. Vazquez, and S. P. Litran, "Instantaneous Reactive Power Theory to N Wire Systems," 2007 IEEE International Symposium on Industrial Electronics, Vigo, pp. 2457-2462, 2007.

[19] P. Salmerón and R. S. Herrera, "Instantaneous Reactive Power Theory, A General Approach to Poly-Phase Systems," Electric Power Systems Research, vol. 79, no. 9, pp. 1263-1270, Sep. 2009.

[20] A. J. Ustariz, E. A. Cano, and H. E. Tacca, "Tensor Analysis of the Instantaneous Power in Electrical Networks," Electric Power Systems Research, vol. 80, no. 7, pp. 788-798, Jul. 2010.

[21] A. J. Ustariz, E. Cano Plata, and H. E. Tacca, "Instantaneous Power Tensor Theory: Improvement And Assessment Of The Electric Power Quality," Proceedings of 14th International Conference on Harmonics and Quality of Power-ICHQP 2010, Bergamo, pp. 1-6, 2010.

[22] M. I. M. Montero, E. R. Cadaval, and F. B. Gonzalez, "Comparison of Control Strategies for Shunt Active Power Filters in Three-Phase Four-Wire Systems," in IEEE Transactions on Power Electronics, vol. 22, no. 1, pp. 229-236, Jan. 2007.

[23] V. Khadkikar, P. Agarwal, A. Chandra, A. O. Barry, and T. D. Nguyen, "A Simple New Control Technique for Unified Power Quality Conditioner (UPQC)," 2004 11th International Conference on Harmonics and Quality of Power (IEEE Cat. No.04EX951), Lake Placid, NY, USA, pp. 289-293, 2004.

[24] K. Vadirajacharya, P. Agarwal, and H. O. Gupta, "Control of Current-Source Active Power Filter using Unit Vector Template in Three Phase Four Wire Unbalnced System," 2007 7th International Conference on Power Electronics and Drive Systems, Bangkok, pp. 1683-1688, 2007.

[25] Yash P. A. L., A. SWARUP, and Bhim SINGH, "New Control Algorithms for Three-Phase Four-Wire Unified Power Quality Conditioner, a simulation study," Electrical Power Quality and Utilisation, Journal, vol. 16, no. 1, pp. 1-10, 2013

[26] Hirofumi Akagi, Akira Nabae, and Satoshi Atoh, "Control Strategy of Active Power Filters Using Multiple Voltage-Source PWM Converters," in IEEE Transactions on Industry Applications, vol. IA-22, no. 3, pp. 460-465, May 1986.

[27] S. Raja Mohamed, P. Aruna Jeyanthy, D. Devaraj, "Hysteresis-Based Voltage and Current Control Techniques for Grid Connected Solar Photovoltaic Systems: Comparative Study," International Journal of Electrical and Computer Engineering (IJECE), vol. 8, no, 5, pp. 2671-2681, Oct. 2018.

\section{BIOGRAPHIES OF AUTHORS}

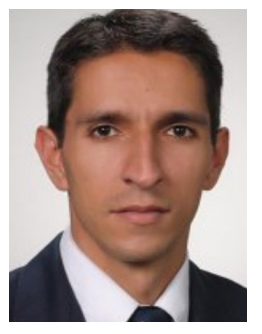

Yeison A. Garces: Electrical Engineer, M.Sc (Eng) Industrial Automation, Ph.D. on Engineering. Associated Professor, UAFCNM, Universidad Católica de Manizales, Manizales, Colombia.E-mail: ygarces@ucm.edu.co. His research interests include power definitions under no sinusoidal conditions, power quality analysis, and power electronic applications. He is member of the Research Group on Tecnhonological and Environmental Development GIDTA and Education and Educators Traning EFE. http://orcid.org/0000-0002-9409-3652.

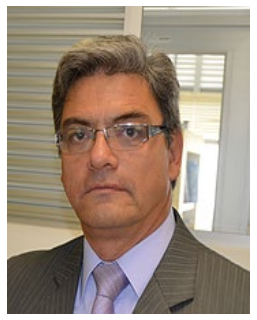

Nicolás Toro: received the B.S. degree in electrical engineering and the Ph.D. degree in automatics from Universidad Nacional de Colombia, Manizales, in 1983 and 2012 respectively; the M.S. degree in production automatic systems from Universidad Tecnológica de Pereira, Colombia, in 2000. He is currently an Associate Professor in the Department of Electrical Engineering, Electronics, and Computer Science, Universidad Nacional de Colombia, sede de Manizales. His research interests include nonlinear control, nonlinear dynamics of nonsmooth systems, and power electronic converters. He is a member of the reasearch group in power resources GIRE (Código colombiano de registro: COL0144229), at the Universidad Nacional de Colombia. https://orcid.org/0000-0001-8317-4126.

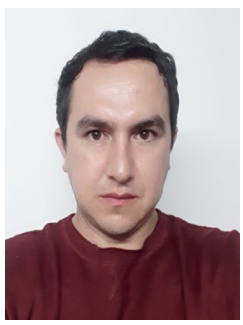

Fredy Edimer Hoyos: from La Cruz, Nariño, Colombia, received his BS and MS degree from the National University of Colombia, at Manizales, Colombia, in Electrical Engineering and Industrial Automation, in 2006 and 2009, respectively, and his Ph.D. in Engineering with an emphasis in Automation in 2012. Dr. Hoyos is currently an Associate Professor of the Science Faculty, School of Physics, at the National University of Colombia, at Medellin, Colombia. His research interests include nonlinear control, system modelling, nonlinear dynamics analysis, control of nonsmooth systems, and power electronics, with application within a broad area of technological process. Dr. Hoyos is an Associate Researcher in Colciencias and member of the Applied Technologies Research Group - GITA at the Universidad Nacional de Colombia. https://orcid.org/0000-0001-8766-5192. 